\title{
Comparative life cycle assessment of carbon fiber reinforced composite components for automotive industry
}

\begin{abstract}
Archimede Forcellese, Tommaso Mancia, Michela Simoncini, Serena Gentili, Marco Marconi, Alessio Vita, Alessia
\end{abstract}
Nardinocchi and Vincenzo Castorani

\author{
Archimede Forcellese. Università Politecnica delle Marche, Via Brecce Bianche 12, 60131 Ancona, Italy. \\ Tommaso Mancia. Università Politecnica delle Marche, Via Brecce Bianche 12, 60131 Ancona, Italy. \\ Michela Simoncini. Università eCampus, Via Isimbardi 10, 22060 Novedrate (CO), Italy. \\ Serena Gentili. Università Politecnica delle Marche, Via Brecce Bianche 12, 60131 Ancona, Italy. \\ Marco Marconi. Università degli Studi della Tuscia, Largo dell’Università, 01100 Viterbo, Italy. \\ Alessio Vita. Università Politecnica delle Marche, Via Brecce Bianche 12, 60131 Ancona, Italy. \\ Corresponding author: alessio.vita@univpm.it \\ Alessia Nardinocchi. HP Composites s.p.a., Zona Ind. Campolungo, 63100 Ascoli Piceno (AP), Italy. \\ Vincenzo Castorani. HP Composites s.p.a., Zona Ind. Campolungo, 63100 Ascoli Piceno (AP), Itally.
}

\begin{abstract}
Advanced materials, especially carbon fiber reinforced composites (CFRP), have gained the attention of different industries which

produce lightweight and high-performance components. The most used manufacturing processes to realize these kinds of products are Resin Transfer Molding (RTM) and vacuum bag molding with autoclave curing. RTM is based on dry fiber technology and it appears the most promising manufacturing process to realized high-quality carbon fiber parts reducing cost and manufacturing time, especially if high pressure variants are employed. On the other hand, vacuum bag molding with autoclave curing is a very consolidated process which is, however, associated with long manufacturing time and costs as well as to low repeatability of the process due to the high labor input. Out-of-autoclave methods, such as pressure bag molding (PBM) have been developed to overcome the issues of vacuum bag molding process. From the environmental point of view, the manufacturing of CFRP components is associated with high environmental loads due to the impacts related to both raw materials and manufacturing processes. For this reason, reducing the energy consumption of production phases can lead to the development of greener CFRP products. In this context, the main scope of the present research is to evaluate and compare the environmental loads of a component for the automotive industry realized exploiting the RTM, the PBM and the bag molding processes to determine which one is ecofriendlier. This analysis has been conducted following the standard Life Cycle Assessment methodology based on a "cradle to gate" approach. In this way, the use phase and the disposal of the CFRP component have not been included in the analysis. Results have been evaluated by comparing the equivalent $\mathrm{CO} 2$ related to each manufacturing process.
\end{abstract}

Keywords. CFRP, Carbon Fiber Composites LCA, Environmental Impacts, RTM, PBM

\section{Introduction}

Moving towards sustainable processes is a mandatory task to realize greener components for the automotive industries [1]. This is especially true as these components are used in eco-friendly products such as electric vehicles (EVs) [2]. However, as well known, the efficiency of EVs is limited mainly due to the high weight of batteries. A method to improve the kilometric range of EVs is to lighten structural and non-structural components [3]. In this context, CFRP (Carbon Fiber Reinforced Polymer) composites, due to their impressive resistance-to-weight and stiffness-to-weight ratios, are increasingly attracting the attention of car manufacturers as valid replacements for metals [4, 5]. Moreover, different studies demonstrated that the use of CFRP in substitution of steel for the production of car structures, in a life cycle perspective, can lead to a reduction of environmental impacts, especially if long lifetime is assured $[6,7]$. This can be attributed to the lowest fuel consumption of the vehicle realized in composite materials even though their 
Comparative life cycle assessment of carbon fiber reinforced compositecomponents for au...

manufacturing and the EoL (End of Life) phases result in higher impacts respect to the ones of steel [8]. Indeed, CFRP composites (especially those based on thermoset matrix) cannot be recycled and their production processes require significant quantities of energy.

According to literature, the production of raw carbon fibers can account for more than $50 \%$ of the total environmental loads of the manufacturing of a CFRP product [9]. However, an important share of these impacts is related to the manufacturing processes exploited to realize composite components. Indeed, to consolidate thermoset matrix and to obtain the higher mechanical performances, composites are cured at high temperature and pressure, thus requiring an intensive use of energy carriers.

One of the most used manufacturing techniques for producing high performance CFRP products is vacuum bag molding with autoclave curing. It needs long lay-up and curing times, as well as high manufacturing costs. In addition, this process is related to high environmental loads as compared to other manufacturing techniques $[6,10]$.

OOA (Out-Of-Autoclave) methods allow to overcome the above-mentioned limitations of autoclave curing. As an example, dry fibers technologies such as Resin Transfer Molding (RTM) have been recognized as valid alternative methods to produce high performance composite components. To shorten processing time, injection pressure can be increased, thus performing High-Pressure RTM (HP-RTM) instead of Low-Pressure (LP-RTM) and Compression (CRTM) RTM [11-13]. However, to do that, heavier and more expensive equipment (such as molds, pumps, presses, etc.) are required. From the environmental point of view, this results in an increase of the environmental loads [14].

Another OOA method which is gaining the attention of industries is PBM (Pressure Bag Molding) [15]. Using this method, it is possible to reduce the cycle time of at least $30 \%$ respect to the autoclave process. However, as reported by Vita et al. [16], PBM could results in higher environmental impacts respect to vacuum bag molding with autoclave curing as CFRP molds are used.

All of the aforementioned processes allow to produce high performance composite components. However, in literature no researches are found concerning the comparison of these manufacturing techniques from an environmental point of view. For this reason, in this paper, vacuum bag molding with autoclave curing, PBM, HP-RTM, LP-RTM and C-RTM are compared analyzing the environmental loads related to each process in a life cycle perspective, according to ISO 140044 and 14040. A reference CFRP component for the automotive industry has been considered to assess the environmental aspects associated to all the phases of the different techniques, from raw material extraction to the end of manufacturing.

\section{Process variants description}

In this study five different production processes were compared from an environmental point of view: Low PressureRTM (LPRTM), High Pressure-RTM (HP-RTM), Compression-RTM (C-RTM), Pressure Bag Molding (PBM) and vacuum bag molding with autoclave curing.

RTM is a closed-mold process as reinforcing dry fibers are placed inside a closed mold before the injection of a liquid thermoset resin. The mold is heated to the adequate temperature that allows the matrix curing. LP-RTM is a modification of the conventional RTM process, the less expensive one in terms of equipment used. It employs lower resin injection pressure and final hydrostatic pressure during the curing cycle. Vacuum is used to clamp molds and helps the resin flow across the fiber pack. The standard cycle time has a duration of 30-60 minutes, considering the typical injection pressure of 10-20 bars [12]. HP-RTM is able to reduce cycle times to less than 10 minutes using injection pressures up to 150bars. These pressures cause high tooling costs and movements of dry fibers inside the molds (a binder is used to hold the fibers in position) [17]. C-RTM further reduces cycle times (injection and impregnation) respect to the HP-RTM. During the injection phase, a gap is present between the dry preform and the countermold, 
which gives less resistance to the resin flow. The injection pressure is typically equal to 5-10 bars [13].

The autoclave processing is performed laminating a preimpregnated material, prepreg, on a CFRP mold. Then, a vacuum bag is realized and the curing occurs in an autoclave at high temperature and pressure for long time, typically more than $100^{\circ} \mathrm{C}, 2$ bar and 2 hours, respectively. The CFRP mold is realized stacking prepreg sheets over a plastic master, typically made of a polyurethane foam (Ureol囚) and performing a complete vacuum bag process with autoclave curing. The useful life of a plastic master is 10 uses and then disposed in landfills, while the mold can be used, before surface degrades, for 150 times [18].

In the PBM process, a silicone counter-mold, manufactured by a curing reaction in an oven, is used to consolidate the CFRP prepreg sheets, laminated over a mold, at a pressure of 6-8bar. The mold is typically made of aluminum and heavy mass is required to withstand the high press pressure generated by a press and by the countermold. The demolding phase requires an energy intensive cooling system [15].

\section{Life cycle assessment}

The Life Cycle Assessment methodology has been used to assess and compare the five different process alternatives. Analyses have been conducted by following the methodology and guidelines foreseen in the ISO 14040 - 14044 standards, which includes four steps: (i) Goal and scope definition, to define objective, functional unit and system boundaries; (ii) Life Cycle Inventory (LCI),

to "decompose" the system under analysis in different unit processes and perform an input-output analysis; (iii) Life Cycle Impact Assessment (LCIA), to calculate the impact in terms of different impact and damage categories; (iv) Results Interpretation, to analyze the obtained results, identify criticalities and define possible improvement strategies.

The Simapro 8.0.5.13 software tool, which includes the Ecoinvent 3.1 as database for secondary data, has been used to model the analyses and calculate the results.

\subsection{Goal and scope}

The objective of the study consists in comparing the environmental impacts of five process alternatives for the manufacturing of CFRP components for the automotive sector: (i) Autoclave; (ii) Pressure bag molding; (iii) Compression resin transfer molding; (iv) High pressure resin transfer molding; (v) Low pressure resin transfer molding. The study can be useful for manufacturing companies involved in the CFRP sector in order to choose the best process alternative to pursue environmental sustainability of their manufacturing activities.

The part considered in the study is a fender of a high-performance sport car with a surface of about 1,3 $\mathrm{m} 2$ and a weight of the finished part of about $1 \mathrm{~kg}$. Despite the five different process alternatives, generally lead to parts with different mechanical properties (parts manufactured through autoclave processes have the best performances followed by PBM and then RTM), in this case the CFRP fenders can be considered comparable from the LCA point of view since no advanced mechanical performances are required, and its adoption in sports car are only related to vehicle lightweighting strategies (i.e. substitution of metal parts). Therefore, the common functional unit can be defined as "the production of a CFRP fender with the abovementioned dimensions, through different manufacturing processes".

The study can be classified as a cradle to gate analysis, since all the unit processes from material production to manufacturing of the finished part have been analyzed, while distribution, use in the car and end of life are not included in the study. The impact assessment methods have been chosen by considering the most relevant impact and damage categories for the CFRP sector, according to previous literature studies [10, 19-21]: 
Comparative life cycle assessment of carbon fiber reinforced compositecomponents for au...

- ReCiPe midpoint [22] to calculate the impact in terms of 18 different categories in order to have a comprehensive overview about the environmental performance of the system under analysis;

- ReCiPe endpoint [22] to normalize and weigh the 18 midpoint indicators, obtaining results in terms of three damage categories (i.e. Ecosystems, Resources, Human health) and finally an aggregated single score.

A graphic explanation of the presented manufacturing processes and the relative system boundary is reported in Fig. 1.

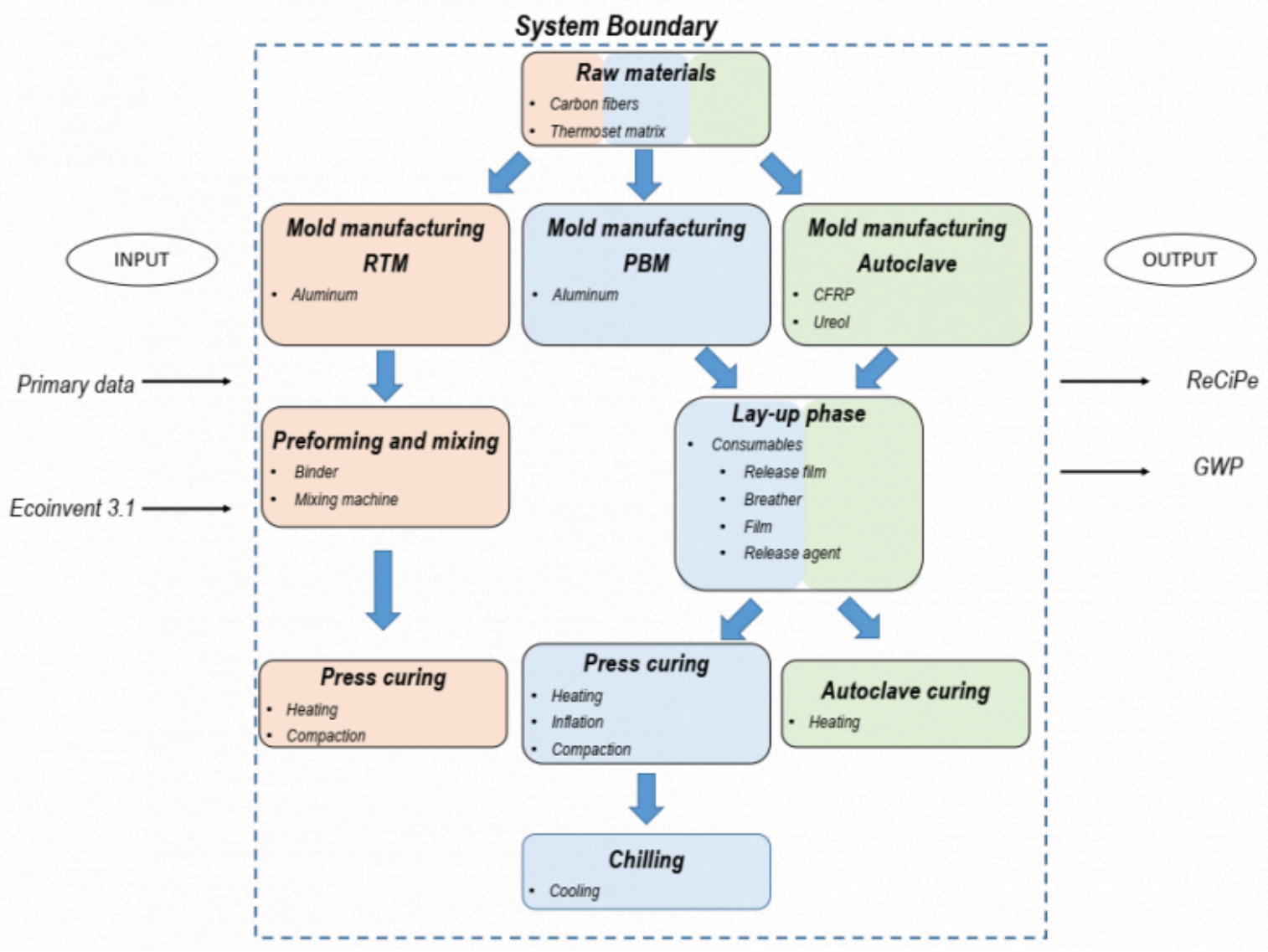

Fig. 1: The investigated manufacturing processes and the relative manufacturing phases.

\subsection{Life cycle inventory}

The LCI is based on measured and estimated data, as well as data derived from relevant literature studies. The following Table 1 reports the full inventory data used in the LCA, together with the details about the data sources.

Table 1. Inventory data 
ESAFORM 2021. MS06 (Chains \& Sustainability)), 10.25518/esaform21.2542

\begin{tabular}{|c|c|c|c|c|}
\hline $\begin{array}{l}\text { Process } \\
\text { alternatives }\end{array}$ & $\begin{array}{l}\text { Process sub- } \\
\text { steps }\end{array}$ & Input-output flows & Quantity & Data Source \\
\hline \multirow{11}{*}{ Autoclave } & \multirow{2}{*}{ Cutting } & $\begin{array}{l}\text { Input Prepreg (66\% carbon fiber, } 34 \% \text { epoxy } \\
\text { resin) }\end{array}$ & $1,68 \mathrm{~kg}$ & $\begin{array}{l}\text { Weight measured } \\
\text { Fiber and prepreg modelling derived from [9] }\end{array}$ \\
\hline & & Cutting machine (Electric energy) & $0,062 \mathrm{kWh}$ & $\begin{array}{l}\text { Estimated from cutting machine consumption } \\
\text { and part perimeter) }\end{array}$ \\
\hline & \multirow{5}{*}{ Lay-up } & Vacuum bag (Polyamide 66) & $0,27 \mathrm{~kg}$ & Measured \\
\hline & & Peel ply (Polyamide 66) & $0,013 \mathrm{~kg}$ & Measured \\
\hline & & Breather (Polyethylene terephthalate) & $0,45 \mathrm{~kg}$ & Measured \\
\hline & & Release film (Polytetrafluoroethylene) & $0,0,041 \mathrm{~kg}$ & Measured \\
\hline & & Release agent (Organic solvent) & $0,015 \mathrm{~kg}$ & Measured \\
\hline & Curing & Autoclave (Electric energy) & $17 \mathrm{kWh}$ & $\begin{array}{l}\text { Estimated from autoclave consumption and cycle } \\
\text { time }\end{array}$ \\
\hline & De-molding & - & - & - \\
\hline & \multirow{2}{*}{ Tooling } & $\begin{array}{l}\text { Master (Ureol) } \\
\text { Master Life: } 10 \text { cycles }\end{array}$ & $100 \mathrm{~kg}$ & Estimated from master 3D model \\
\hline & & $\begin{array}{l}\text { Mold (CFRP) } \\
\text { Mold Life: } 150 \text { cycles }\end{array}$ & $11,34 \mathrm{~kg}$ & Estimated from mold 3D model \\
\hline \multirow{12}{*}{ PBM } & \multirow{2}{*}{ Cutting } & $\begin{array}{l}\text { Input Prepreg ( } 66 \% \text { carbon fiber, } 34 \% \text { epoxy } \\
\text { resin) }\end{array}$ & $1,68 \mathrm{~kg}$ & $\begin{array}{l}\text { Weight measured } \\
\text { Fiber and prepreg modelling derived from [9] }\end{array}$ \\
\hline & & Cutting machine (Electric energy) & $0,062 \mathrm{kWh}$ & $\begin{array}{l}\text { Estimated from cutting machine consumption } \\
\text { and part perimeter }\end{array}$ \\
\hline & \multirow{4}{*}{ Lay-up } & Film (Polytetrafluoroethylene) & $0,046 \mathrm{~kg}$ & Measured \\
\hline & & Breather (Polyethylene terephthalate) & $0,2 \mathrm{~kg}$ & Measured \\
\hline & & Release film (Polytetrafluoroethylene) & $0,0,025 \mathrm{~kg}$ & Measured \\
\hline & & Release agent (Organic solvent) & $0,015 \mathrm{~kg}$ & Measured \\
\hline & \multirow{3}{*}{ Curing } & Heating (Electric energy) & $51 \mathrm{kWh}$ & Measured \\
\hline & & Clamping (Electric energy) & $4,2 \mathrm{kWh}$ & Measured \\
\hline & & Inflation (Compressed air) & $0,51 \mathrm{~m}^{3}$ & Measured \\
\hline & De-molding & Chilling (Electric energy) & $14 \mathrm{kWh}$ & Measured \\
\hline & \multirow{2}{*}{ Tooling } & $\begin{array}{l}\text { Mold (Aluminum) } \\
\text { Mold Life: } 750 \text { cycles }\end{array}$ & $873 \mathrm{~kg}$ & Estimated from mold 3D model \\
\hline & & $\begin{array}{l}\text { Counter-mold (Silicon rubber) } \\
\text { Counter-mold Life: } 750 \text { cycles } \\
\end{array}$ & $8 \mathrm{~kg}$ & Measured \\
\hline \multirow{9}{*}{ C-RTM } & \multirow{3}{*}{ Preforming } & Carbon fiber & $0,67 \mathrm{~kg}$ & $\begin{array}{l}\text { Weight measured } \\
\text { Fiber modelling derived from [9] }\end{array}$ \\
\hline & & Epoxy resin & $0,35 \mathrm{~kg}$ & $\begin{array}{l}\text { Weight measured } \\
\text { Fiber modelling derived from [9] }\end{array}$ \\
\hline & & Preforming (Electric energy) & $1,7 \mathrm{kWh}$ & Measured \\
\hline & \multirow{2}{*}{ Mixing machine } & Injection (Electric energy) & $0,9 \mathrm{kWh}$ & Measured \\
\hline & & Matrix heating (Electric energy) & $0,7 \mathrm{kWh}$ & Measured \\
\hline & \multirow{3}{*}{ Molding } & Heating (Electric energy) & $5,2 \mathrm{kWh}$ & Measured \\
\hline & & Cooling (Electric energy) & $2,4 \mathrm{kWh}$ & Measured \\
\hline & & Clamping (Electric energy) & $0,7 \mathrm{kWh}$ & Measured \\
\hline & Mold & $\begin{array}{l}\text { Mold (Aluminum) } \\
\text { Mold Life: } 750 \text { cycles }\end{array}$ & $380 \mathrm{~kg}$ & Estimated from mold 3D model \\
\hline
\end{tabular}


Comparative life cycle assessment of carbon fiber reinforced compositecomponents for au...

\begin{tabular}{|c|c|c|c|c|}
\hline \multirow{9}{*}{ HP-RTM } & \multirow{3}{*}{ Preforming } & Carbon fiber & $0,67 \mathrm{~kg}$ & $\begin{array}{l}\text { Weight measured } \\
\text { Fiber modelling derived from [9] }\end{array}$ \\
\hline & & Epoxy resin & $0,35 \mathrm{~kg}$ & $\begin{array}{l}\text { Weight measured } \\
\text { Fiber modelling derived from [9] }\end{array}$ \\
\hline & & Preforming (Electric energy) & $1,7 \mathrm{kWh}$ & Measured \\
\hline & \multirow{2}{*}{ Mixing machine } & Injection (Electric energy) & $1,3 \mathrm{kWh}$ & Measured \\
\hline & & Matrix heating (Electric energy) & $1,3 \mathrm{kWh}$ & Measured \\
\hline & \multirow{3}{*}{ Molding } & Heating (Electric energy) & $9,3 \mathrm{kWh}$ & Measured \\
\hline & & Cooling (Electric energy) & $4 \mathrm{kWh}$ & Measured \\
\hline & & Clamping (Electric energy) & $8,1 \mathrm{kWh}$ & Measured \\
\hline & Mold & $\begin{array}{l}\text { Mold (Aluminum) } \\
\text { Mold Life: } 750 \text { cycles }\end{array}$ & $1610 \mathrm{~kg}$ & Estimated from mold 3D model \\
\hline \multirow{9}{*}{ LP-RTM } & \multirow{3}{*}{ Preforming } & Carbon fiber & $0,67 \mathrm{~kg}$ & $\begin{array}{l}\text { Weight measured } \\
\text { Fiber modelling derived from [9] }\end{array}$ \\
\hline & & Epoxy resin & $0,35 \mathrm{~kg}$ & $\begin{array}{l}\text { Weight measured } \\
\text { Fiber modelling derived from [9] }\end{array}$ \\
\hline & & Preforming (Electric energy) & $1,9 \mathrm{kWh}$ & Measured \\
\hline & \multirow{2}{*}{ Mixing machine } & Injection (Electric energy) & $6,6 \mathrm{kWh}$ & Measured \\
\hline & & Matrix heating (Electric energy) & $2,4 \mathrm{kWh}$ & Measured \\
\hline & \multirow{3}{*}{ Molding } & Heating (Electric energy) & $12,5 \mathrm{kWh}$ & Measured \\
\hline & & Cooling (Electric energy) & $11 \mathrm{kWh}$ & Measured \\
\hline & & Clamping (Electric energy) & $10,1 \mathrm{kWh}$ & Measured \\
\hline & Mold & $\begin{array}{l}\text { Mold (Aluminum) } \\
\text { Mold Life: } 750 \text { cycles }\end{array}$ & $610 \mathrm{~kg}$ & Estimated from mold 3D model \\
\hline
\end{tabular}

\subsection{Results assessment and interpretation}

The first Life Cycle Impact Assessment (LCIA) has been performed by jointly considering all the midpoint indicators included in the ReCiPe methodology. The following Table 2 reports the results obtained for each CFRP manufacturing process, with the indication of the best (green cells) and worst (red cells) alternatives for each impact category. For the purpose of comparison, Fig. 2 reports a normalized comparison to highlight the percentage saving of each alternative in comparison with the worst alternative in each impact category. The applied normalization consists in dividing the obtained results in each impact category by the maximum results obtained.

In this way the worst alternative has a 100\% value and the savings can be easily visualized.

Table 2. ReCiPe midpoint categories results 


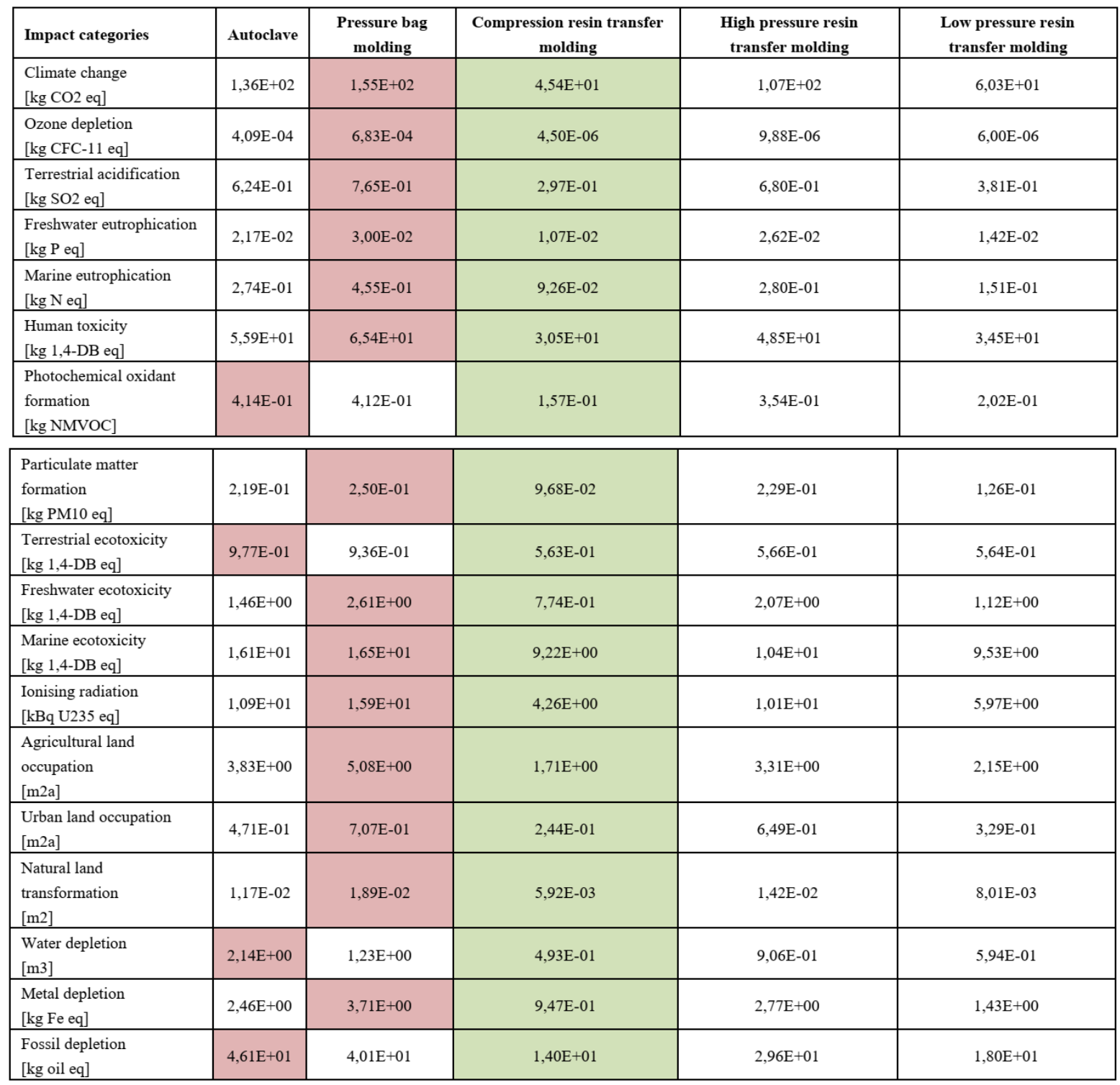




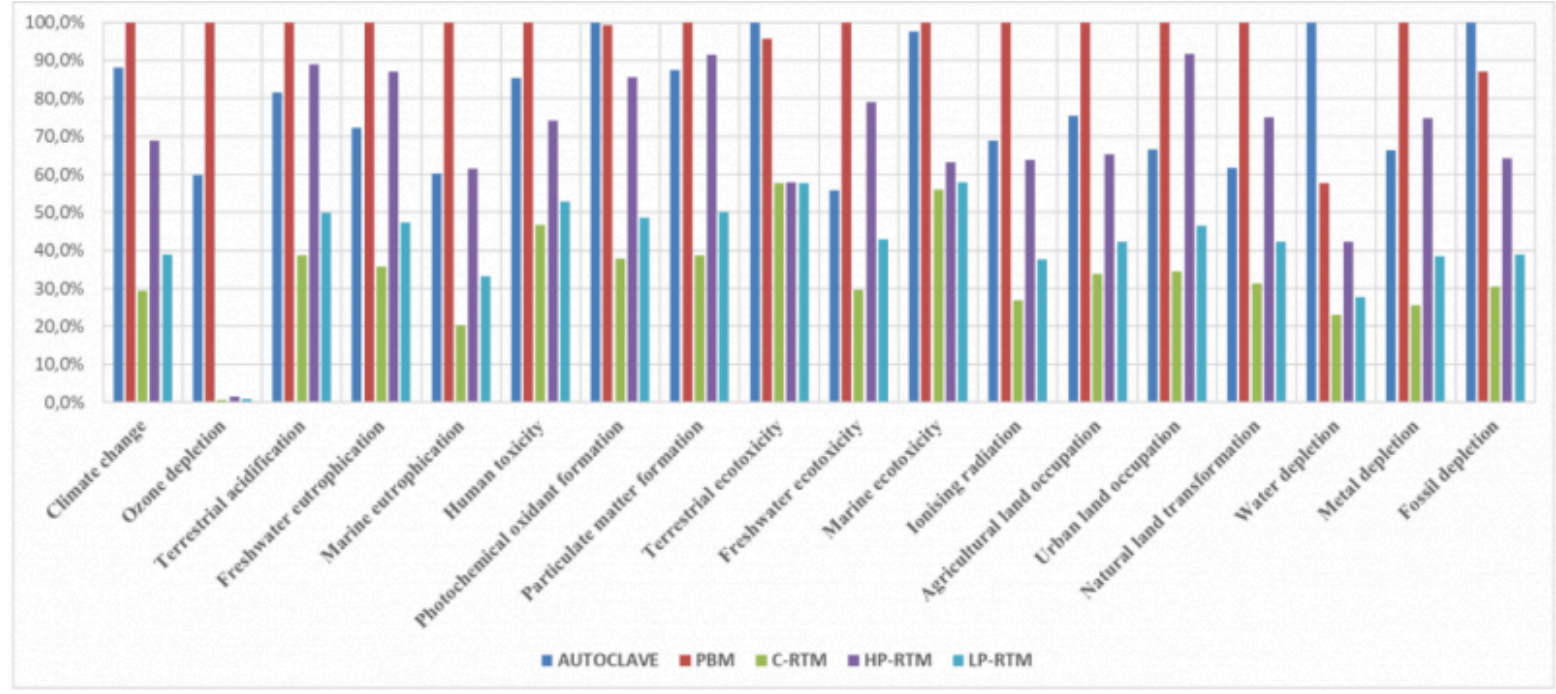

Fig. 2. ReCiPe normalized comparison

From the ReCiPe midpoint analysis, the clearest conclusion is related to the best process alternative: regardless of the considered impact category, the most sustainable process is the C-RTM. The savings against the worst alternatives are relevant and range from 42,4\%, in case of Terrestrial ecotoxicity, to $99,3 \%$ in case of Ozone depletion. The worst alternative, instead, is almost always the

PBM process, except for Photochemical oxidant formation, Terrestrial ecotoxicity, Water depletion and Fossil depletion where the worst alternative is the Autoclave process. Leaving aside the first two indicators for which the differences among the PBM and Autoclave are minimal, for the other two impact categories the results are mainly due to the use of a large amount of Ureol to manufacture the master in case of Autoclave. Comparing the three RTM variants, the results highlight that C-RTM is always the best alternative, LP-RTM is an "intermediate" solution, while HP-RTM is always the worst process variant. For some of the ReCiPe midpoint categories (i.e., Terrestrial acidification, Freshwater eutrophication, Marine eutrophication, Particulate matter formation, Freshwater ecotoxicity, Urban land occupation, Natural land transformation, Metal depletion) this latter globally represents the second worst alternative. In all the cases the main reasons are the use of large quantities of aluminum to manufacture the mold and the high consumption of electric energy for heating, cooling and clamping during the molding phase.

Going into more details in one of the most relevant categories for the manufacturing sector, and in particular for CFRP [10, 19-21], the following Fig. 3 reports the split of contributions for the Global Warming Potential indicator (i.e. ReCiPe Climate Change). In this case the best alternative is the C-RTM, followed by the LP-RTM, the HP-RTM, the Autoclave, and finally the PBM as the most impactful process. Split of contributions highlight that for almost all the process the most critical flow is the production of carbon fibers, included within the Cutting contribution for Autoclave and PBM, and Preforming for the three RTM variants. However, there is a substantial difference among Autoclave/ PBM, where Cutting contributes for 57,05 kgCO2eq, and RTM variants, where Preforming contributes for less than a half, 26,32 kgCO2eq. The main reason of this large difference is the major efficiency of the RTM process in the use of carbon fibers, because in case of Autoclave/PBM the prepreg sheets have to be cut with the generation of large amount of scraps, while in case of RTM the scraps are almost null. This is confirmed by the inventory data reported in Table 1, where for Autoclave/PBM processes the input carbon fibers are about 1,10 $\mathrm{kg}$ ( $66 \%$ of 1,68 $\mathrm{kg}$ of prepreg), against only $0,67 \mathrm{~kg}$ in case of RTM processes. Another minor cause is the use of dry fibers in case of RTM, instead of prepreg, 
in case of Autoclave/PBM, which requires consumption of energy for the prepregging phase [9].

Considering Autoclave, the second largest contribution is the Tooling (about 36\% of the total impact), that is mainly due to the manufacturing of the Ureol master (more than $90 \%$ of the Tooling contribution). For PBM, the contribution of Tooling is relevant but minor than in case of Autoclave (29,61 vs 49,86 kgCO2eq). The most penalizing contribution is certainly the Curing, and specifically the critical flow is the energy consumption for heating the mold. In addition, in this case also the De-molding phase generates impacts due to the energy consumption needed for cooling the mold before the part extraction. Such two contributions make the PBM the worst process in terms of GWP.

Considering RTM, instead, the different dimensions of aluminum molds for the three variants (380 kg for C-RTM, 1610 $\mathrm{kg}$ for HPRTM and $610 \mathrm{~kg}$ for LP-RTM) cause relevant differences in terms of GWP impacts (46,02 kgC02eq, 17,61 kgC02eq and11,27 kgCO2eq, respectively). In addition, the mold dimensions are directly correlated to the electric energy needed for mold heating during the resin curing, another aspect that enlarge the differences among C-RTM, LP-RTM and HP-RTM (in order of total impact).

\begin{tabular}{|c|c|c|c|c|c|c|}
\hline \multirow{7}{*}{ 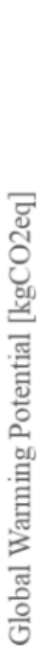 } & \multicolumn{6}{|l|}{160,00} \\
\hline & \multicolumn{6}{|l|}{140,00} \\
\hline & \multicolumn{6}{|l|}{120,00} \\
\hline & \multicolumn{6}{|l|}{100,00} \\
\hline & \multicolumn{6}{|l|}{80,00} \\
\hline & \multicolumn{6}{|l|}{60,00} \\
\hline & \multicolumn{6}{|l|}{40,00} \\
\hline & \multicolumn{6}{|l|}{20,00} \\
\hline & 0,00 & AUTOCLAVE & PBM & C-RTM & HP-RTM & LP-RTM \\
\hline \multicolumn{2}{|c|}{ - MOULD } & & & 11,27 & 46,02 & 17,61 \\
\hline \multicolumn{2}{|c|}{ - MIXING MACHINE } & & & 3,39 & 8,10 & 4,02 \\
\hline \multicolumn{2}{|c|}{ MOLDING } & & & 4,84 & 26,80 & 12,80 \\
\hline \multicolumn{2}{|c|}{ PREFORMING } & & & 26,32 & 26,69 & 26,36 \\
\hline \multicolumn{2}{|c|}{ TOOLING } & 49,86 & 29,61 & & & \\
\hline \multicolumn{2}{|c|}{ - DE-MOULDING } & 0,00 & 8,91 & & & \\
\hline \multicolumn{2}{|c|}{ = CURING } & 10,82 & 35,18 & & & \\
\hline \multicolumn{2}{|c|}{ - LAY-UP } & 19,59 & 23,70 & & & \\
\hline \multicolumn{2}{|c|}{ - CUTTING } & 57,05 & 57,05 & & & \\
\hline
\end{tabular}

Fig. 3. Split of contributions in terms of Global Warming Potential midpoint category.

Finally, a ReCiPe endpoint analysis has been performed, as reported in the following Fig. 4. As expected, the worst alternatives are PBM and Autoclave for which about the same impacts have been obtained (14,90 Pt for PBM vs 14,78 Pt for Autoclave): the savings for Curing in Autoclave vs PBM (1,07 vs 3,48 Pt) are "compensated" by the largest impacts for the Tooling (5,77 vs 2,69 Pt). Once again, the RTM variants demonstrated to be more sustainable processes, in line 
Comparative life cycle assessment of carbon fiber reinforced compositecomponents for au...

with the results previously obtained with the ReCiPe midpoint analyses.

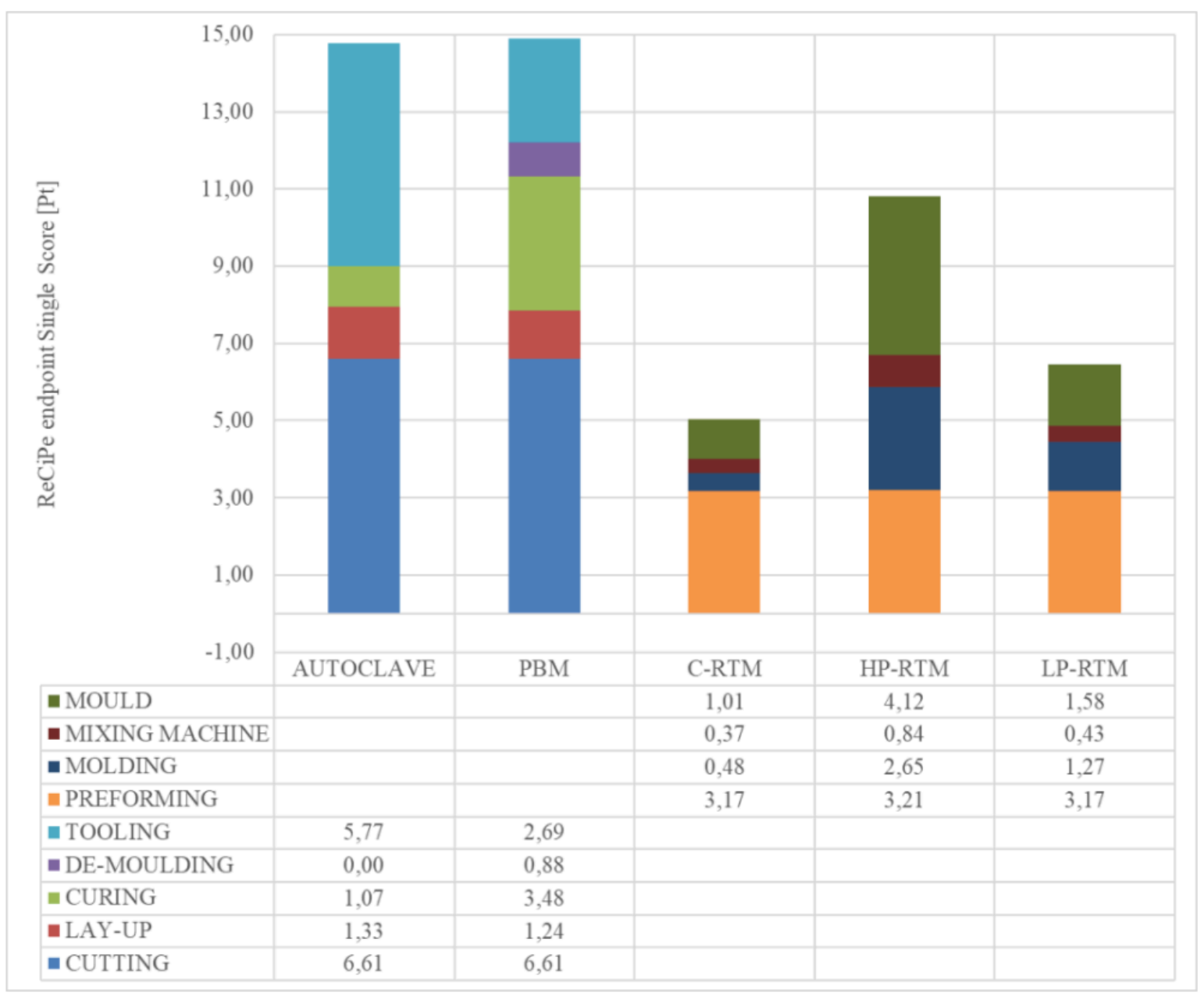

Fig. 4. Split of contributions in terms of ReCiPe endpoint Single Score

\section{Conclusion}

In this research, five manufacturing processes for the obtaining of CFRP components have been compared from the environmental point of view. One process is bag molding with autoclave curing and the others are three RTM variants (High Pressure, Low Pressure and Compression) and pressure bag molding (PBM). The reported LCA analyses include all the phases from raw materials extraction

to the end of the manufacturing process of a typical component for the automotive industry.

The obtained results show that:

- The manufacturing of carbon fiber and epoxy resin is the most relevant environmental load for the analyzed processes;

- RTM techniques are associated to lower environmental impacts with respect to both PBM and autoclave;

- C-RTM results the greener manufacturing process, mainly due to the lightness of the mold;

- Autoclave and PBM are the worst processes. This can be attributed to the prepregging phase and to the high impacts 
related to the manufacturing of aluminum and CFRP molds as well as of the Ureol master.

\section{Bibliography}

[1] Landi, D., Marconi, M., Bocci, E., Germani, M.: Comparative life cycle assessment of standard, cellulose-reinforced and end of life tires fiber-reinforced hot mix asphalt mixtures. J. Clean. Prod. 248, 119295 (2020).

doi:10.1016/j.jclepro.2019.119295

[2] Mathes, V.: The composites industry: plenty of opportunities in heterogeneous market. Reinf. Plast. 62, 44-51 (2018). doi:10.1016/J.REPL.2017.05.002

[3] Suzuki, T., Takahashi, J.: Prediction of energy intensity of carbon fiber reinforced plastics for mass-produced passenger cars. Ninth Japan Int. SAMPE Symp. JISSE-9. 14-19 (2005)

[4] Delogu, M., Zanchi, L., Dattilo, C.A., Pierini, M.: Innovative composites and hybrid materials for electric vehicles lightweight design in a sustainability perspective. Mater. Today Commun. 13, 192-209 (2017).

doi:10.1016/j.mtcomm.2017.09.012

[5] Das, S.: Life cycle assessment of carbon fiber-reinforced polymer composites. Int. J. Life Cycle Assess. 16, 268-282 (2011). doi:10.1007/s11367-011-0264-z

[6] Song, Y.S., Youn, J.R., Gutowski, T.G.: Life cycle energy analysis of fiber-reinforced composites. Compos. Part A Appl. Sci. Manuf. 40, 1257-1265 (2009). doi:10.1016/j.compositesa.2009.05.020

[7] Duflou, J.R., De Moor, J., Verpoest, I., Dewulf, W.: Environmental impact analysis of composite use in car manufacturing. CIRP Ann. - Manuf. Technol. 58, 9-12 (2009). doi:10.1016/j.cirp.2009.03.077

[8] Scelsi, L., Bonner, M., Hodzic, A., Soutis, C., Wilson, C., Scaife, R., Ridgway, K.: Potential emissions savings of lightweight composite aircraft components evaluated through life cycle assessment. Express Polym. Lett. 5, 209-217 (2011). doi:10.3144/expresspolymlett.2011.20

[9] Forcellese, A., Marconi, M., Simoncini, M., Vita, A.: Life cycle impact assessment of different manufacturing technologies for automotive CFRP components. J. Clean. Prod. 271, 122677 (2020). doi:10.1016/j.jclepro.2020.122677

[10] Witik, R.A., Payet, J., Michaud, V., Ludwig, C., Månson, J.A.E.: Assessing the life cycle costs and environmental performance of lightweight materials in automobile applications. Compos. Part A Appl. Sci. Manuf. 42, 1694-1709 (2011). doi:10.1016/j.compositesa.2011.07.024

[11] Bhat, P., Merotte, J., Simacek, P., Advani, S.G.: Process analysis of compression resin transfer molding. Compos. Part A Appl. Sci. Manuf. 40, 431-441 (2009). doi:10.1016/j.compositesa.2009.01.006

[12] Davenport, D.E., Petrovich, R., Sutton, G.: Low Pressure Resin Transfer Molding for Cost Effective Aircraft Quality Structures. (2007)

[13] Baskaran, M., Sarrionandia, M., Aurrekoetxea, J., Acosta, J., Argarate, U., Chico, D.: Manufacturing cost comparison of RTM, HP-RTM and CRTM for an automotive roof. ECCM16 16th Eur. Conf. Compos. Mater. 22-26 (2014)

[14] Vita, A., Castorani, V., Germani, M., Marconi, M.: Comparative Life Cycle Assessment of Low-Pressure RTM, 
Comparative life cycle assessment of carbon fiber reinforced compositecomponents for au...

Compression RTM and High-Pressure RTM manufacturing processes to produce CFRP car hoods. Procedia CIRP. (2018)

[15] Crivelli Visconti, I., Langella, A.: Analytical modelling of pressure bag technology. Compos. Manuf. 3, 3-6 (1992). doi:10.1016/0956-7143(92)90176-U

[16] Vita, A., Castorani, V., Germani, M., Marconi, M.: Comparative life cycle assessment and cost analysis of autoclave and pressure bag molding for producing CFRP components. Int. J. Adv. Manuf. Technol. (2019). doi:10.1007/ s00170-019-04384-9

[17] R. Chaudhari, P. Rosenberg, M. Karcher, S. Schmidhuber, P. Elsner, F.H.: HIGH-PRESSURE RTM PROCESS VARIANTS FOR MANFUACTURING OF CARBON FIBER REINFORCED COMPOSITES. In: 19Th International Conference on Composite Materials

[18] Loos, A.C. (Alfred C.., Hyer, M.W., American Society for Composites.: Manufacturing of composites.

[19] Duflou, J.R., Deng, Y., Van Acker, K., Dewulf, W.: Do fiber-reinforced polymer composites provide environmentally benign alternatives? A life-cycleassessment-based study. MRS Bull. 37, 374-382 (2012). doi:10.1557/mrs.2012.33

[20] Khalil, Y.F.: Eco-efficient lightweight carbon-fiber reinforced polymer for environmentally greener commercial aviation industry. Sustain. Prod. Consum. 12, 16-26 (2017). doi:10.1016/j.spc.2017.05.004

[21] Raugei, M., Morrey, D., Hutchinson, A., Winfield, P.: A coherent life cycle assessment of a range of lightweighting strategies for compact vehicles. J. Clean. Prod. 108, 1168-1176 (2015). doi:10.1016/j.jclepro.2015.05.100

[22] Goedkoop, M., Heijungs, R., De Schryver, A., Struijs, J., van Zelm, R.: ReCiPe 2008. A LCIA method which comprises harmonised category indicators at the midpoint and the endpoint level. Characterisation. A life cycle impact .... 133 (2008). doi:http://www.lcia-recipe.net

PDF automatically generated on 2021-05-20 05:37:45

Article url: https://popups.uliege.be/esaform21/index.php?id=2542

published by ULiège Library in Open Access under the terms and conditions of the CC-BY License

(https://creativecommons.org/licenses/by/4.0) 